\title{
Applications of Super Critical Fluid Extraction in Milk and Dairy Industry: A Review
}

\author{
Shyam Kumar Singh*, Maddikunta Sai Pavan, Sai Prasanna N and Rajni Kant \\ Agricultural and Food Engineering Department Indian Institute of Technology, Kharagpur, 721302, India
}

\begin{abstract}
In the present scenario of growing population and environmental concerns, consumers are having huge preferences towards healthier, minimally processed and long shelf stable foods which in turn paved the way to develop new functional dairy products. Numerous and wider range of possible methods with better nutritional emphasis and enhanced functionality of dairy foods were emerging. Super Critical Fluid Extraction (SCFE) is one amongst the processes which is currently becoming popular in modifying different food products to produce new ones. This SCFE gained prominence as an alternative to green technology in the food processing industry. It is a fluid phase extraction processing method which operates in between a gas and liquid and induces solubilization of solutes in a base food material. In this method, supercritical fluids most commonly $\mathrm{CO}_{2}$ is used as a solvent to separate one selective component from the base food material. SCFE can be varied for different foods upon altering the two factors, i.e., pressure and temperature or both. The products obtained in milk and dairy processing with use of SCFE had a higher shelf life and acceptable sensorial properties with minimal loss of quality attributes. In this review, some studies related to the potential of SCFE and its microbial inactivation, milk fat analysis, milk fat fractionation and fat solubility, extraction of cholesterol, vitamins, flavours, fat and applications of SCFE technology in dairy products and by-products more specifically in butter, cheese, whey cream and buttermilk were discussed briefly.
\end{abstract}

Keywords: Functional dairy products; Supercritical fluid extraction; Milk fractionation; SCFE applications

\section{Introduction}

In the present world, food scientists, manufacturers and consumers became more health conscious and demand for processed foods without loss of the nutritive value and organoleptic properties of foods along with improving the shelf life on inhibiting or killing microorganisms [1]. This demand paved way for non-thermal technologies without the use of preservatives or additives for processing food products maintaining color, flavor, texture, nutritive and functional qualities at acceptable levels that are minimally processed, easily handled, good quality and safe [2]. Emerging non thermal methods particularly used in milk processing are cold plasma technology [3-5], atmospheric pressure encapsulated Dielectric Barrier Discharge (DBD) plasma technology [6], ohmic heating [7-9], high pressure processing [10,11], pulsed electric field $[12,13]$, supercritical fluid technology [14], ultra-violet irradiation [15,16], pulsed light treatment [17], microfiltration [18,19] and ultrasound treatment $[20,21]$ resulted in efficient inactivation of pathogens and significant improvements in nutritional, sensory and quality attributes with prolonged shelf life compared to conventional methods. Among these technologies, SCFE has fruitful benefits like separation of desired or selective compounds with no traces of toxic solvent residues in the resulting food products, lesser chances for thermal degradation of the processed products, an appreciable level of nutrient retention and higher efficiency [22,23]. The selective separation of compounds through SCFE mainly depended upon two reasons i.e., supercritical fluids has higher diffusivity than gases and lower viscosity than liquid solvents. These factors resulted in a higher rate for mass transfer of solutes into the fluid [24] In this review, the various types of supercritical fluid techniques used in milk processing and dairy industry, how the treatment affected various physical, chemical, microbial and other related properties were discussed here.

\section{Theory Behind Supercritical Technology}

The supercritical condition is the state at which component (substance) temperature and pressure are above its critical values where gas and liquid are indistinguishable from each other. Supercritical coordinates and supercritical region of Carbon Dioxide are illustrated in Figure 1.

In case of a fluid, when it forced to a pressure and temperature higher than its critical limit, then it termed as Supercritical Fluid (SCF). Under these conditions, the SCF behaves like both gas and liquid i.e. properties of SCF lies between gases and liquids. SCF is extensively using in extraction processes due to their functional physiochemical properties such as density, diffusivity, dielectric constant, viscosity, solvating power, flow properties etc. SCF having some properties similar to gases and liquids hence, they are indiscernible. SCF is having a density close to that of liquids, viscosity near to that of gases and diffusivity is moderate between gases and liquids. They behave like compressible fluids (gases) and have similar density and solvating power of those liquids.

Usage of SCF in extraction processes is increasing tremendously day by day because of various physiochemical characteristics of SCF which helps in providing operational benefits over traditional extraction techniques. Since, conventional extraction methods are time-consuming, laborious, low selectivity and low extraction yields. Furthermore, traditional techniques use toxic solvents in excessive amounts. These drawbacks of traditional methods can be overcome by SCF extraction technology. SCF provides attractive features that deal with the limitations facing in conventional extraction methods. SCF are

*Corresponding author: Shyam Kumar Singh, Agricultural and Food Engineering Department Indian Institute of Technology, Kharagpur, 721302 India, Tel: +918876877706; E-mail: shyamsingh.iitkgp@gmail.com

Received October 04, 2018; Accepted November 13, 2018; Published November 16,2018

Citation: Singh SK, Pavan MS, Sai Prasanna N, Kant R (2018) Applications of Super Critical Fluid Extraction in Milk and Dairy Industry: A Review. J Food Process Technol 9: 769. doi: 10.4172/2157-7110.1000769

Copyright: (c) 2018 Singh SK, et al. This is an open-access article distributed unde the terms of the Creative Commons Attribution License, which permits unrestricted use, distribution, and reproduction in any medium, provided the original author and source are credited. 


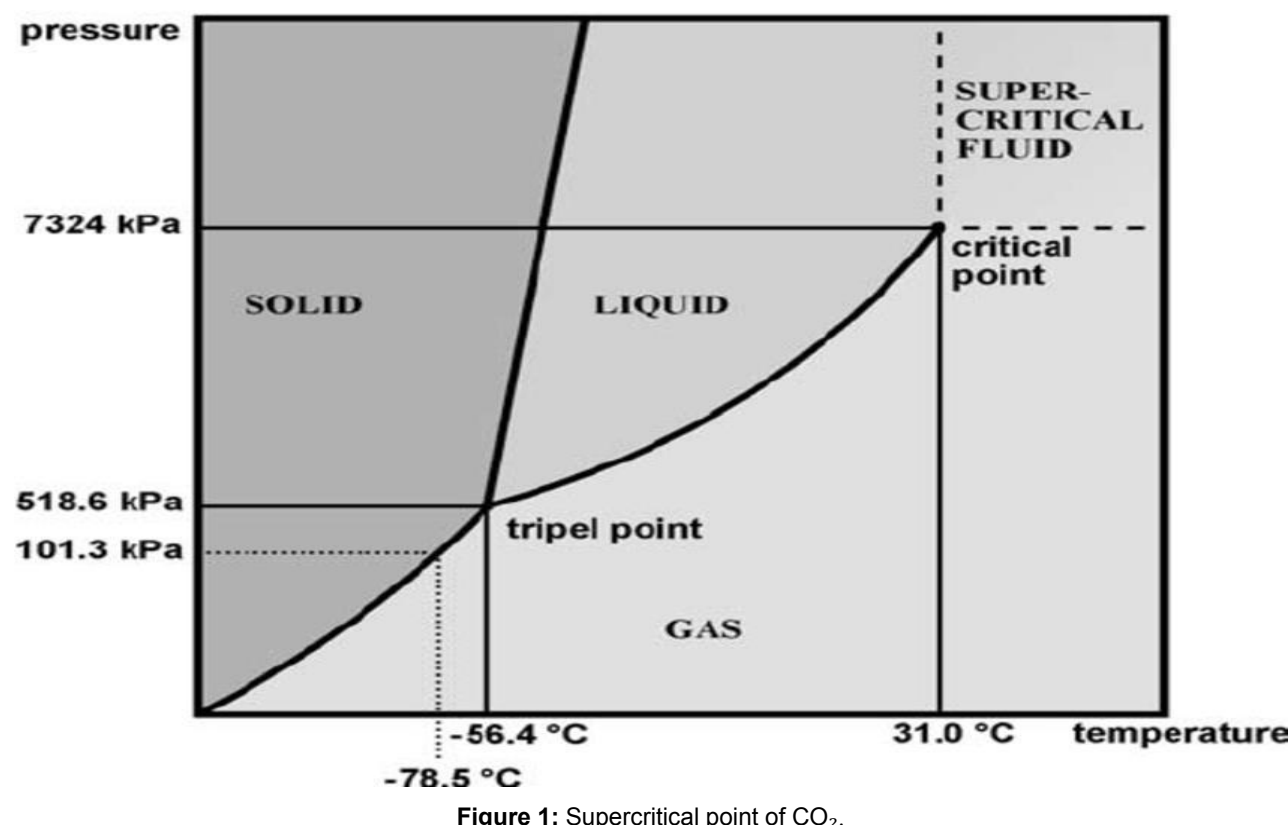

possessing significantly lower viscosity and relatively higher diffusivity which promotes the transport properties (flow properties) of fluid. In addition to higher diffusivity, SCF is also possessing the stupendous capacity to dissolve. Thus, enhanced diffusion and solubility take place in the solid matrix resulting in accelerated extraction rates with higher yields than those of traditional solvent extraction methods. The main aid of SCF is that its density since, solvent strength of SCF is a function of density which plays a vital role in controlling solvent power by altering temperature or pressure. Another unique characteristic of SCF is their selectivity. By tuning, temperature or pressure or both extraction selectivity of SCF towards target compound can be altered [25]. This allows SCF for extracting numerous ranges of target compounds $[25,26]$ mentioned that extraction selectivity can be altered by adding co-solvent such as ethanol, methanol, hexane, acetone, chloroform, water etc. to promote or demote polarity depending on requirement.

Numerous fluids can be used as supercritical fluids listed in Table 1. Among the list of supercritical fluids, supercritical Carbon dioxide $\left(\mathrm{SC}-\mathrm{CO}_{2}\right)$ is the mostly used fluid in SCF extraction process because of its low critical coordinates. The critical point of $\mathrm{SC}-\mathrm{CO}_{2}$ is $3^{\circ} \mathrm{C}$ of temperature and $7.38 \mathrm{MPa}$ of pressure. Moreover, $\mathrm{SC}-\mathrm{CO}_{2}$ is having some specific advantages made it more suitable fluid in the extraction process are abundance, non-in flammability, cheap, its volatility, nonpolarity. Due to its volatile nature, target extract obtained is solvent free i.e. extract always in its pure form or without any $\mathrm{SC}-\mathrm{CO}_{2}$.

\section{Steps involved in SCF extraction}

The extraction process involves two steps namely, extraction and separation. In the first step, fluid is heated and pressurized above critical point depending on target compound and allow it to the extractor setup where extraction takes place. The second step is to separate the solvent and extracted material in the separator. SCF turns into gaseous form after depressurization. Here, separation is based on gravity. Subsequently, SCF can be recycled or released into the atmosphere.

Scientists and researchers have been acquainted with SCF from a long back but SCF solvents have been the focus on active research and development from past few decades. Even though the SCF extraction method has several advantages over conventional methods, high capital investment is required to set up the equipment. This is the main obstacle for industry scale commercialization of SCF technologies. However, SCF techniques reduce the processing steps resulting in a significant reduction in processing costs. Additionally, the supercritical extraction process is a green extraction technology.

\section{Application of SCFE in the milk industry}

Milk is the lactic secretion produced by the mammary gland of all female mammals which provides the nourishment to humans $[27,28]$. Milk is consumed by all ages of people, but it is highly perishable and being spoiled by microorganisms. So the safety, microbial quality and shelf life of milk are the most considerable factors during milk processing, preservation, storage and marketing [29]. During thermal processing of milk, changes occur in certain heat-labile nutrients, vitamins, minerals etc., which impairs the nutritive value of milk, precipitation of calcium phosphate, the occurrence of Maillard reactions and water-soluble vitamins are also mainly affected. Severe heating or Prolonged storage or severe heating causes whey protein denaturation which may affect the flavor of the milk [30]. But these effects can be controlled to appreciable levels with the application of SCFE. The milk fat, vitamins, and cholesterols extracted from milk using SCFE technique have resulted in inappropriate results.

\section{SCFE in milk fat analysis}

The food industry utilizes milk fat mostly in butter and anhydrous milk fat [31]. Generally, simple bench-top Supercritical Fluid Extraction (SFE) systems utilizing $\mathrm{CO}_{2}$ proved to be effective in measuring total fat content in the food matrices such as dairy products, meats, and seeds [32].

Determination of fat content is very much essential in all milk processing industries. The organic solvents used in soxhlet apparatus causes the environmental release of hazardous materials. The SCFE with on-line piezoelectric detection used very small amounts of samples to analyze the fat content in milk products and significantly reduced the dangers with exposure to hazardous materials [33]. 


\begin{tabular}{|c|c|cc|cc|}
\hline \multirow{2}{*}{ S. No. } & \multirow{2}{*}{ Fluids } & \multicolumn{2}{|c|}{ Critical point } & \multicolumn{2}{c|}{ Properties } \\
\cline { 3 - 6 } & & $\begin{array}{c}\text { Temperature } \\
\text { ('C) }\end{array}$ & $\begin{array}{c}\text { Pressure } \\
\text { (MPa) }\end{array}$ & $\begin{array}{c}\text { Density } \mathbf{( g /} / \\
\mathbf{m L})\end{array}$ & $\begin{array}{c}\text { Solubility } \\
\left.\text { (cal- } \mathbf{1 / 2} \mathbf{~ c m}^{-3 / 2}\right)\end{array}$ \\
\hline 1. & Carbon Dioxide & 31.2 & 72.9 & 0.470 & 7.5 \\
\hline 2. & Ethane & 32.4 & 48.2 & 0.200 & 5.8 \\
\hline 3. & Ethene & 10.1 & 50.5 & 0.200 & 5.8 \\
\hline 4. & Methanol & -34.4 & 79.9 & 0.272 & 8.9 \\
\hline 5. & Nitrous Oxide & 36.7 & 71.7 & 0.460 & 7.2 \\
\hline 6. & n-Butene & -139.9 & 36.0 & 0.221 & 5.2 \\
\hline 7. & n-Pentane & -76.5 & 33.3 & 0.237 & 5.1 \\
\hline 8. & $\begin{array}{c}\text { Sulfur } \\
\text { hexafluoride }\end{array}$ & 45.8 & 37.7 & 0.730 & 5.5 \\
\hline 9. & Water & 101.1 & 217.6 & 0.322 & 13.5 \\
\hline
\end{tabular}

Table 1: Properties of supercritical fluids (da Silva et al. 2016) [27]

\section{SCFE in milk fat vitamins and flavor determination}

Turner et al. [34] used SFE followed by a saponification and HPLC for the fat-soluble vitamins $\mathrm{A}$ and $\mathrm{E}$ determination in milk powder with SFE conditions: $37 \mathrm{MPa}, 80^{\circ} \mathrm{C}, 15 \mathrm{~min}$ static and $15 \mathrm{~min}$ dynamic extraction, $1.0 \mathrm{ml} / \mathrm{min}$, collection into $16 \mathrm{ml}$ of ethanol-diisopropyl ether $(1: 1)$ at $58^{\circ} \mathrm{C}$. The milk samples were wetted with $2.0 \mathrm{ml}$ of methanol or ethanol and a reference sample with no modifier added was extracted with $\mathrm{CO}_{2}$ containing $5 \%$ of methanol. The SFE with good recoveries above $99 \%$ for vitamin A and $96 \%$ for vitamin E were occurring in milk powder [34].

Haan et al. [35] extracted flavor components from milk fat using supercritical fluid extraction. Since carbon dioxide has a critical temperature $\left(31.1^{\circ} \mathrm{C}\right)$, nontoxic, non-flammable, inexpensive and has a high purity and these properties made to choose $\mathrm{CO}_{2}$ as an ideal solvent for extracting flavor components from the milk fat which also helped in retaining its natural value. The process conditions for flavor extraction depended upon the carbon dioxide density, temperature, solvent-tofeed ratio on the extracted content, the concentration factor and the fraction of flavor components extracted from the milk fat. Mainly, two steps were used to analyze the flavor components in the feed, i.e., the extract and the raffinate. Firstly, the flavor components were separated from the triglycerides with HPLC followed by capillary gas chromatography for the flavor fraction analysis. Here the extraction has two stages. In the very first stage, the flavor components from the triglycerides were separated and the second stage was used to obtain a maximum concentration factor. The decrease in $\mathrm{CO}_{2}$ density increased the concentration factor in the first extraction stage and decrease in the extraction temperature resulted in higher concentration factors in the second stage. The fraction of flavor components was increased as much as possible particularly at low extraction temperature, increasing the number of equilibrium stages in the column and a small solvent-tofeed ratio [35]. Low-fat cheese products were developed in the dairy industry which utilizes SFE technology and retains flavor compounds [36].

\section{Milk Fat Fractionation}

Milk fat is composed primarily of triglycerides (or triacylglycerides) is $98 \%$ of the total milk fat (by weight). Other milk lipids (as a percentage of the total milk fat) include: diacylglycerides $(0.25$ $0.48 \%)$; monoacylglycerides (0.02-0.04\%); phospholipids (0.6-1.0\%); cholesterol (0.2-0.4\%); glycolipids (0.006\%); and free fatty acids in milk (0.1-0.4\%). Crystallization at a different temperature is a common method for milk fat fractionation with or without the use of solvents $[37,38]$. Though solvents or surfactants are able to separate triglyceride effectively, solvent removal creates a problem. Chemical methods such as inter-esterification [39] and hydrogenation [40] for milk fat modification results in loss of many desired characteristics and extinguish natural flavor. Such restrictions are not found with SCFE.

Shishikura et al. [41] conducted an experiment using a single pass unit at a pressure of $150 \mathrm{Kg} / \mathrm{cm}^{2}$ and temperature of $40^{\circ} \mathrm{C}$. They reported that triglyceride with less than 36 carbons i.e. short chain triglyceride was especially concentrated in the initial two fractions, while those with 38 and 40 carbon units were concentrated constantly all through the extraction process. Triglycerides with more than 40 carbon units show an increment through the process of extraction and especially, glycerides with more than 46 carbons were concentrated in final extraction and in residual oils. Arul et al., [42] fractionated milk fat into 8 fractions using supercritical carbon dioxide for the temperature of $50^{\circ} \mathrm{C}$ and $70^{\circ} \mathrm{C}$ and, for a pressure range of $10-35 \mathrm{MPa}$. The 8 fractions are shown in Table 2.

The authors found that the fraction of the short chain triglycerides (C24-C34) gradually decreased from $\mathrm{Ll}$ to S3, while L2 and I-3 were rich in medium chain triglycerides. On the other hand, compared to milk fat, fractions S2 and S3, were low in both short and medium chain triglycerides. There is an increase in long-chain triglyceride from L1 to S3 and are mostly concentrated in fractions S2 and S3. Another study was conducted by Bhaskar et al., [37], they divided the milk fat into 5 fractions namely S1, S2, S3, S4, and S5 respectively in the pressure range of 241-34 bar and temperatures range of $40^{\circ} \mathrm{C}-75^{\circ} \mathrm{C}$. They observed that the fractions S1 to S5 show a gradual increase in short-chain (C4-C8) and medium-chain (ClO-C12) fatty acids, while a reverse case was observed with the long-chain and unsaturated fatty acids (C14-C18).

\section{Milk fat solubility in supercritical carbon dioxide}

The solubility of a substance tends to increase with the increase in pressure with temperature being constant, because solubility of any substance is mostly dependent on the van der walls, but influence of temperature on solution equilibrium is slightly complicated, beyond a certain pressure (which is specific for solvent-solute) the solubility increases with increasing temperature [43]. Arul et al. [43] found that smaller triglycerides exhibited a greater supercritical carbon dioxide solvent capacity than the larger ones. This is because with the increase of pressure at constant temperature volatility or fugacity of the triglyceride phase increases. The vapor pressure of triglycerides

\begin{tabular}{|c|c|c|c|}
\hline Fraction & State at room temperature & Weight (g) & Yield (\%) \\
\hline Milk fat (feed) & Solid & 6.05 & - \\
\hline L1 & Liquid & 0.25 & 4.1 \\
\hline L2 & Liquid & 0.48 & 8.1 \\
\hline LFa & Liquid & 0.73 & 12.2 \\
\hline I1 & Semi-solid & 0.57 & 9.4 \\
\hline I2 & Semi-solid & 0.80 & 13.5 \\
\hline I3 & Semi-solid & 0.95 & 15.7 \\
\hline IFb & Semi-solid & 2.32 & 38.2 \\
\hline S1 & Solid & 0.65 & 10.7 \\
\hline S2 & Solid & 1.05 & 17.3 \\
\hline S3 & Solid & 1.30 & 21.5 \\
\hline \multicolumn{2}{|c|}{ SFc } & 3.00 & 49.5 \\
\hline $\begin{array}{l}\text { TTotal liquid fraction } \\
\text { Total intermediate fraction } \\
\text { cTotal solid fraction }\end{array}$ \\
\hline
\end{tabular}

Table 2: Yield of different milk fat fractions by supercritical carbon dioxide (Arul et al. [42]). 
decreases with their carbon number [44] and therefore, the short-chain triglycerides are, in general, more volatile than long chain molecules.

Short chain triglycerides, on the other hand, have higher absolute vapor pressure due to their higher volatility, up to a certain pressure than that of long-chain molecules. Taking into consideration all these factors short chain triglycerides versus have more solubility than the long chain molecules at low pressure. However, long-chain triglyceride has higher solubility at higher pressure short chain triglyceride.

Arul et al. [43] found that solubility of milk fat triglyceride was higher for $50^{\circ} \mathrm{C}$ than for $80^{\circ} \mathrm{C}$ at a constant pressure (say 200 bar) because at that pressure the heat of mixing is exothermic, and hence, solutesolvent attractive orientations are favored at a lower temperature. But, that was not the case always, because above a pressure of $250 \mathrm{bar}$, the heat of mixing becomes endothermic and solubility of triglyceride increases with increasing temperature [45].

\section{Extraction of milk fat globule membrane (MFGM) phospholipids and proteins using a combination of techniques}

Costa et al., [46] developed a dairy ingredient with the use of whey buttermilk as raw material and produced dairy powder enriched in Milk Fat Globule Membrane (MFGM) phospholipids and proteins using the combination of ultrafiltration/diafiltration membrane filtration and supercritical fluid extraction technologies. Concentrate of whey buttermilk was spray-dried and subjected to three extraction cycles using Supercritical Fluid Extraction (SFE) with conditions: 1.5 $\mathrm{kg}$ of $\mathrm{CO}_{2}$ at a flow rate of $0.02 \mathrm{~kg} / \mathrm{min}$, extraction pressure of $35 \mathrm{MPa}$ at a temperature of $50^{\circ} \mathrm{C}$, after the membrane filtration. Phospholipids enriched dairy powders have found their application in food formulations like ice cream, powdered soup mix or bakery delicacies [46].

The Milk Fat Globule Membrane (MFGM) contains phospholipids in buttermilk. Polar MFGM lipids and proteins can be concentrated from buttermilk using microfiltration and supercritical fluid extraction technologies and were used at various levels in different dairy components [47]. Also, microfiltration, when coupled with supercritical fluid extraction, can be incorporated as nutritional valued lipids into a novel ingredient. SFE provide phospholipid enrichment and used for optimizing the lipid removal effectiveness. With the addition of physical aids like removable Teflon beads, fluidized bed mixing systems makes adequate removal of nonpolar lipids for enriching polar lipid [48].

Phospholipids (PLs) were associated with health and nutritional benefits related to cognitive development and repair. A Pilot scale production of a dairy ingredient enriched in phospholipids (PLs) was generated from a Buttermilk Powder (BMP) substrate. In this respect, a combined process of targeted enzymatic hydrolysis of the innate milk proteins and ultrafiltration of the smaller molecular weight peptide material was followed. Purified PLs fraction was achieved through SFE. From an industrial point, the dairy products which were enriched in PLs fortified nutrition in infants and aged people in promoting brain health [49].

\section{Microbial inactivation in milk using SCFE}

Milk is a low acid food, thus allowing development of a range of microorganism, including important pathogens, such as Salmonella, Escherichia coli, Listeria monocytogenes, and Coxiella burnetti, among others [50]. The microbial reduction of aerobic mesophilic bacteria and Escherichia coli in human milk depends upon temperature, pressure and exposure time of SCFE processing using carbon dioxide as a solvent. This reduction will be greater at a higher pressure of $\mathrm{CO}_{2}$. The exposure time for $120 \mathrm{~min}$ and the pressure of $20 \mathrm{MPa}$ had a positive effect on microbial inactivation [51].

The use of supercritical $\mathrm{CO}_{2}$ technology to inactivate microorganisms is a novel method and well reported in the literature and the factors involved were shown in Table 3. Many terms have been used by several authors, such as Dense Phase Carbon Dioxide (DPCD), Liquid Carbon Dioxide (LCD) and High-Pressure Carbon Dioxide (HPCD). The use of supercritical carbon dioxide technology has also aroused interest in the dairy area. In 1987, in Germany, a patent (DE3734025 A1) proposed the use of supercritical $\mathrm{CO}_{2}$ to increase the shelf life of dairy products. Table 3 explains the different reasons behind microbial inactivation using supercritical carbon dioxide.

\section{Milk pasteurization using SCFE}

Supercritical fluid extraction using $\mathrm{CO}_{2}$ as the solvent can be considered as a mild effective pasteurization process which increases the shelf life for skim milk. This process when used with HTST or ultra-pasteurization (cream separated by centrifugation) to produce mild pasteurized whole milk. This whole process is similar to Bactocatch process with 3 sections: homogenization section and thermal pasteurization section (for centrifugal separation of cream) and the SCFE pasteurization treatment section. The optimal operating parameters were the pressure of $15 \mathrm{MPa}$, temperature $35-38^{\circ} \mathrm{C}$, $\mathrm{CO}_{2} /$ skim milk-feed ratio of 0.30:0.33 and residence time of $0.25 \mathrm{hr}$ with a shelf life of 35 days. Also, SCFE pasteurized skim milk has

\begin{tabular}{|c|c|}
\hline Factors & Mechanisms \\
\hline Solubilization & $\begin{array}{l}\mathrm{CO}_{2} \text { in aqueous solution forms carbonic acid }\left(\mathrm{H}_{2} \mathrm{CO}_{3}\right) \text {, which dissociates into bicarbonate }\left(\mathrm{HCO}_{3}\right) \text {, carbonate }\left(\mathrm{CO}_{3}{ }^{2-}\right) \text { and hydrogen } \\
(\mathrm{pH}) \text { ions, thus reducing the interstitial } \mathrm{pH} \text { of the bacterial cell, and reducing microbial resistance to inactivation due to higher energy } \\
\text { consumption for maintaining intracellular homeostasis. }\end{array}$ \\
\hline \multirow[t]{2}{*}{$\begin{array}{l}\text { Structural changes in the cell } \\
\text { Reduction in } \\
\text { intracellular } \mathrm{pH}\end{array}$} & $\begin{array}{l}\text { The high affinity between } \mathrm{CO}_{2} \text { and plasma membrane provides } \mathrm{CO}_{2} \text { accumulation within the internal lipophilic layer, affecting its } \\
\text { permeability, with structural and functional disorders to the microorganism. }\end{array}$ \\
\hline & $\begin{array}{l}\text { The increased permeability of the membrane allows penetration of the pressurized } \mathrm{CO}_{2} \text { across the bacterial cell membrane with } \\
\text { accumulation within the microbial cell. }\end{array}$ \\
\hline Enzyme inactivation & $\begin{array}{l}\text { The reduction in intracellular } \mathrm{pH} \text { can cause inhibition and/or inactivation of essential enzymes for regulating the metabolic processes of } \\
\text { the organism since the catalytic activity of enzymes is particularly sensitive to } \mathrm{pH} \text { change. The immediate consequence is the loss of } \\
\text { biological controls, damaging the intermediary metabolism and cellular function. }\end{array}$ \\
\hline Direct inhibitory & $\begin{array}{l}\text { The concentration of carbonic acid and bicarbonate ion appears to microbial metabolism due to changes in the carboxylation and } \\
\text { decarboxylation of the different reactions. Lethal damage to the biological system of the microbial cells can occur additional dioxide } \\
\text { with pressure and carbon accumulation. }\end{array}$ \\
\hline $\begin{array}{l}\text { Disorder in Removal of the vital } \\
\text { components and cell }\end{array}$ & $\begin{array}{l}\mathrm{CO}_{2} \text { accumulated in the interior of the microbial cell can "extract" vital components from the cell membranes of microorganisms such as } \\
\text { phospholipids and hydrophobic compounds, altering the structure and/or balance of nutrients. }\end{array}$ \\
\hline
\end{tabular}

Table 3: Microbial inactivation mechanism of supercritical $\mathrm{CO}_{2}$ (SOURCE: Adapted from Perrut [52]). 
significantly better taste than thermally pasteurized milk. Continuous SFE process with $\mathrm{CO}_{2}$ solvent was developed for industrial production of non-thermal pasteurization of whole liquid milk [52,53]. Table 4 summarizes the studies on the use of microbial inactivation in milk using supercritical carbon dioxide.

\section{Enzyme activity in milk involved with SCFE}

Alkaline phosphatase was an endogenous enzyme present in milk and slightly more resistant to heat compared to the most pathogenic bacteria. It was used as good indicators for the effectiveness of pasteurization of milk and milk products [54]. In recent times, SCFE processing using $\mathrm{CO}_{2}$ can inactivate enzymes and pathogenic microbes and also the degradation of thermo-labile nutrients of foods at a minimal level, thereby extending their shelf lives and preserves sensory and nutritive values. This process using $\mathrm{CO}_{2}$ is cost effective and also improves mass transfer due to higher $\mathrm{CO}_{2}$ diffusivity. The enzymes increase their activities with SCFE treatment using $\mathrm{CO}_{2}$ [55].

The effects of temperature, pressure, $\mathrm{CO}_{2}$ to milk mass ratio, alkaline phosphatase activity and reduction of activity after the continuous treatment with SCFE with $\mathrm{CO}_{2}$ and with initial alkaline phosphatase activity: $5.5 \mathrm{U} / \mathrm{mL}$ were $30^{\circ} \mathrm{C}, 80$ bar, 0.45 (wt. $\%$ ), $4.2 \mathrm{U} / \mathrm{mL}$ and $-23.6 \%$ with apparent residence time of $30 \mathrm{~min}$. Initial alkaline phosphatase activity was $5.5 \mathrm{U} / \mathrm{mL}$. The optimized condition for continuous inactivation of alkaline phosphatase activity in milk was $\mathrm{CO}_{2}$ to milk mass ratio of $0.05 \mathrm{wt} \%, 70^{\circ} \mathrm{C}, 80 \mathrm{bar}$ and residence time of $30 \mathrm{~min}$ was $1.1 \mathrm{U} / \mathrm{mL}$ with initial alkaline phosphatase activity of $6.4 \mathrm{U} / \mathrm{mL}$ [56].

\section{SCFE for cholesterol determination and removal}

Cholesterol, a sterol is an essential structural component of the animal cell. 100-gram milk contains $13.6 \mathrm{mg}$ of cholesterol. Saturated fat and cholesterol are the primary risk factors for coronary heart diseases if taken above a certain limit. So, there is a growing concern among the consumers about low cholesterol foods. It is being recommended by the American Heart Association to reduce the daily intake of cholesterol and saturated fat [57]. An average American consumes about 500 to $600 \mathrm{mg} / \mathrm{d}$ cholesterol. A maximum intake limit of $300 \mathrm{mg} / \mathrm{d}$ is being suggested by many national institutes of health [58,59]. For all of these reasons, there is a serious concern among the consumers for low cholesterol food, which has forced the researches or scientist to focus on producing low cholesterol products. Steam distillation, crystallization, supercritical fluid extraction, complexing cholesterol with $\beta$-cyclodextrin are some methods to remove cholesterol from food.

Cholesterol extraction from anhydrous milk (AMF) fat using SC$\mathrm{CO}_{2}$ has been widely studied. Anhydrous milk fat is a complicated mixture of triglycerides, which contain several fatty acids of varying degree of saturation and carbon chain length [60]. The solubility of cholesterol and AMF in $\mathrm{SC}-\mathrm{CO}_{2}$ has also been intensively studied [61-63]. Bradly [64], used digitonin procedure for $\beta-3-\mathrm{OH}$ sterols for cholesterol assay. He designed a two-stage processing equipment, the first stage, which operate at low pressure is used for the separation of flavors and triglyceride with low melting points and remainder with cholesterol is conveyed to high-pressure unit i.e., a second stage where cholesterol and high melting triglyceride gets separated. They reported an extraction efficiency of $90 \%$ of cholesterol from milk.

Huber et al. [60] also studied the selective separation of cholesterol from anhydrous milk (AMF). They prepared a mixture of AMF and supercritical fluid (SCF) by dissolving AMF in SCF and passed this mixture through a suitable adsorbent [65]. The extraction process parameters were varied from $80-400$ bar and temperature from 40 ${ }^{\circ} \mathrm{C}-70^{\circ} \mathrm{C}$ for determination of solubility of AMF in SCF and selectivity of cholesterol over AMF. It was found that alone SCF is not feasible for extraction of cholesterol from AMF because the solubility of AMF was poor even at best selectivity conditions $\left(80-100\right.$ bar and $\left.40^{\circ} \mathrm{C}\right)$. Whereas with the incorporation of a silica gel based absorbent of particle size $5-40 \mu \mathrm{m}$ a selective removal of $97 \%$ of the cholesterol from the extracted AMF is possible.

Huber et al. [66] determined the cholesterol in milk fat using supercritical fluid chromatography (SFC). They found that although SCF was more accurate, it was costlier and more time consuming than Gas Chromatography (GS) for analysis of cholesterol in milk fat. Kankare and Alkio [67] found that $99 \%$ of milk cholesterol can be removed by an SCF extraction system equipped with a silica gel column. Their studies also indicated that the fractionation of fat on the basis of the different fatty acid composition can be achieved simultaneously by performing the milk fat extraction using supercritical carbon dioxide and connecting an adsorbent column filled with silica gel to the extraction system.

\section{Isolation of polychlorinated biphenyls from milk using SCFE}

Polychlorinated Biphenyls (PCB) which is widely spread in the environment can make a very highly toxic pollutant and some adverse biological effects have been reported in the literature. The primary causes of PCB are many human activities. PCBs may cause cancer development, immune deficiency disorders and reproductive, nervous or other biological systems malfunction [68]. Cow milk has been reported to contain PCB residues which sometimes exceeds the level $0.2 \mathrm{mg} / \mathrm{l}$ (equivalent to $5.0 \mathrm{mg} / \mathrm{l}$ in milk fat), which is being set by the FDA. Therefore, it is required to remove the excess amount of PCB from milk. A typical process using Soxhlet extraction with an organic solvent would require 3-8 hours or overnight after that is requires evaporation to a low volume and then to isolate PCB from fat a chromatographic clean-up is needed. A study by Mills and Jefferies [69] shows SFE and SFC as a replacement to the traditional practices which reduces cost and time of operation. They used a mixture of freeze-dried skim milk, equivalent to $10 \mathrm{ml}$ of original milk (fat content $0.1 \% \mathrm{w} / \mathrm{w}$ ). They found

\begin{tabular}{|c|c|c|c|c|c|c|}
\hline Product & Microorganism & Pressure (MPa) & Temperature $\left({ }^{\circ}\right)$ & Time (min) & System & Reduction (log) \\
\hline Raw skim milk & Native psychrotrophs & 20.7 & 35 & 10 & Continuous & 5.36 \\
\hline Raw skim milk & Pseudomonas fluorescens & 20.7 & 35 & 10 & Continuous & 5.02 \\
\hline Raw milk & Aerobic bacteria & 25 & 50 & 70 & Continuous & 4.96 \\
\hline Raw milk & Coliforms & 25 & 40 & 50 & Continuous & 2 \\
\hline Raw milk & Yeast and molds & 25 & 40 & 50 & Continuous & 3 \\
\hline Raw milk & Aerobic bacteria & 4 & 45 & 1 & $\mathrm{MBCO}_{2}$ & 3 \\
\hline UHT milk & Escherichia coli & 4 & 50 & 5 & $\mathrm{MBCO}_{2}$ & 4.80 \\
\hline Whole milk & Escherichia coli & 8 & 70 & 1 & Continuous & 0.09 \\
\hline
\end{tabular}

Table 4: Main current studies on the use of supercritical $\mathrm{CO}_{2}$ for microbial inactivation in milk and dairy products (Source: Amaral et al. [50]) 


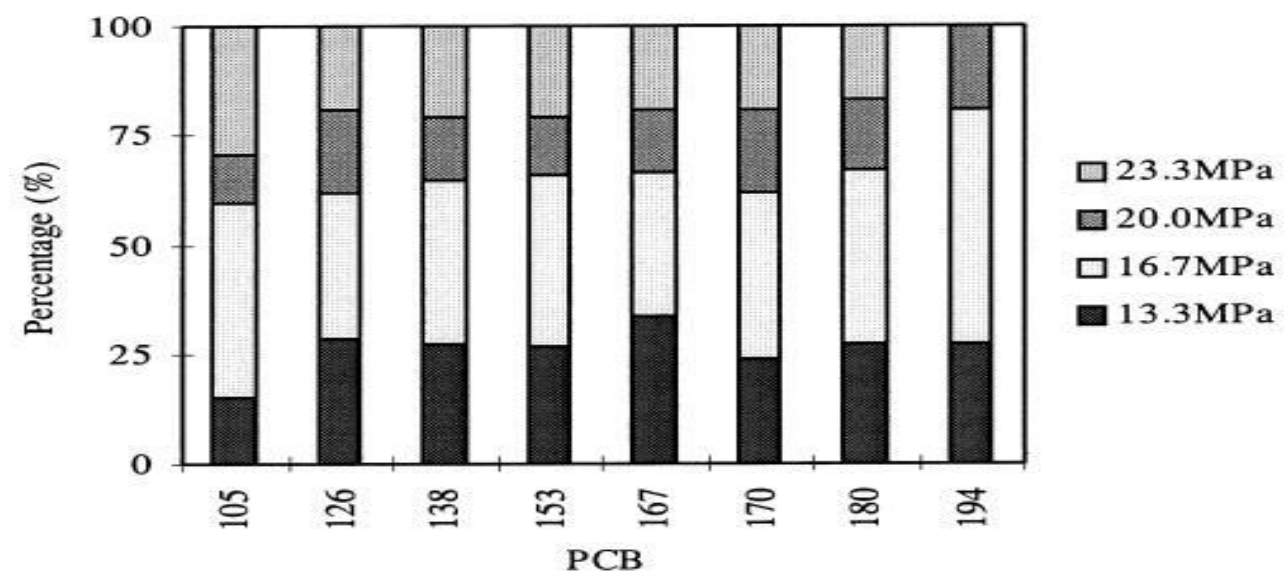

Figure 2: Percentage of PCB found in the four consecutive lipidic fractions extracted by SFE (Source: Ramos et al. [70]).

that the extraction conditions were the same for extraction of both fat and PCB from milk. The extraction condition which they used was: $50^{\circ} \mathrm{C}$ and 160 bar, $45^{\circ} \mathrm{C}$ and 160 bar and $50^{\circ} \mathrm{C}$ and 200 bar.

PCB distribution in milk fat globule for four different lipidic fractions (short-chain triglyceride, medium-chain triglyceride, long chain triglyceride, and cholesterol) by SC- $\mathrm{CO}_{2}$ was studied by Ramos et al. [70]. The experiment was conducted with $6 \mathrm{~g}$ powdered full-fat milk with a moisture content of $4.2 \%$ and at a constant temperature of $50^{\circ} \mathrm{C}$ for varying pressures of 133, 167, 200, 233 bar respectively. Levels of PCB congeners extracted by SFE increased with the pressure from 133 to 167 bar and then decreased for subsequent SFEs. Short-chain and medium-chain triglyceride constituted $59 \%$ and $81 \%$ respectively and long-chain triglyceride and cholesterol constituted in the range of 11$19 \%$ and $0.0-30 \%$ respectively of the total endogenous congener levels extracted by the four consecutive SFEs. Figure 2 below summarises the percentage of PCBs detected in four consecutive lipid fractions extracted by SFE.

\section{Conclusion}

SCFE has grabbed considerable attention in a variety of industries due to its higher solubility, improved mass transfer rates and better optimization of temperature and pressure in the process gave good results. SCFE with $\mathrm{CO}_{2}$ as solvent proved as the green alternative technology providing safety to health and environment in the commercial applications of the dairy industry in various functional dairy food products having good economic and nutrient value. The cholesterol extracted from cream powder using SCFE provided functional foods which satisfied the health-conscious consumers. When buttermilk is subjected to SCFE, concentrates of polar lipids like phospholipids from Milk Fat Globule Membrane (MFGM) were obtained. SCFE can be used as a replacement technology for milk fat analysis instead of traditional methods which requires intensive time and labor and also huge amounts of hazardous organic solvents were used. This process controlled the microbial inactivation at appreciable levels compared to cold pasteurization with minimal loss of vitamins, flavors, nutrients, etc. This extraction process is environmentally friendly since it reduces the amount of the number of solvents, efficient utilization of industrial by-products and also filters the toxic compounds which possess hazards to the environment.

\section{References}

1. Morris C, Brody AL, Wicker L (2007) Non-thermal food processing/preservation technologies: A review with packaging implications. Packag Technol Sci 20: 275-286.

2. Jan A, Sood M, Sofi SA, Norzom T (2017) Non-thermal processing in food applications: A review. Int J Food Sci Nutr 2: 171-180.

3. Korachi M, Ozen F, Aslan N, Vannini L, Guerzoni ME, et al. (2015) Biochemical changes to milk following treatment by a novel, cold atmospheric plasma system. Int Dairy J 42: 64-69.

4. Ruan R, Metzger L, Chen P, Deng S (2010) Non-thermal plasma pasteurization of milk using plasma technology (phase II). Midwest Dairy Foods Research Center 227-231.

5. Gurol C, Ekinci FY, Aslan N, Korachi M (2012) Low temperature plasma for decontamination of $E$. coli in milk. Int J Food Microbiol 157: 1-5.

6. Kim H, Yong HI, Park S, Kim K, Choe W, et al. (2015) Microbial safety and quality attributes of milk following treatment with atmospheric pressure encapsulated dielectric barrier discharge plasma. Food Control 47: 45-456.

7. Kim SS, Kang DH (2015) Effect of milk fat content on the performance of ohmic heating for inactivation of Escherichia coli O157:H7, Salmonella enterica serovar Typhimurium and Listeria monocytogenes. J Appl Microbiol 119: 475486

8. Sun H, Masuda F, Kawamura S, Himoto J, Asano K, et al. (2011) Effect of electric current of ohmic heating on non-thermal injury to Streptococcus thermophilus in milk. J Food Process Eng 34: 878-892.

9. Lanjewar P, Minz PS, Prajapati R. Comparison of ohmic and electric heating of milk. National Seminar on "Indian Dairy Industry-Opportunities and Challenges".

10. Evelyn, Silva FVM (2015) High pressure processing of milk: Modeling the inactivation of psychrotrophic Bacillus cereus spores at $38^{\circ} \mathrm{C}-70^{\circ} \mathrm{C}$. J Food Eng 165: $141-148$.

11. Chopde SS, Deshmukh MA, Kalyankar SD, Changade SP (2014) Applications of high pressure technology for milk processing. Res J Anim Husban Dairy Sci 5: 143-147.

12. Daniela BA, Fernandez S, Esquivel H, Dunne PC, Gustavo VB (2011) Milk processed by pulsed electric fields: Evaluation of microbial quality, physicochemical characteristics, and selected Nutrients at different storage conditions. J Food Sci 76: 289-299.

13. Chaudhari A, Jana AH, Prajapati JP. Application of pulsed electric field for milk processing, national seminar on "Indian Dairy Industry-Opportunities and Challenges.

14. Buyukbese D, Rousseau D, Kaya A (2017) Composition and shear crystallization of milk fat fractions extracted with supercritical carbon dioxide. Int J Food Prop 20: 3015-3026.

15. Wertheim JH, Roychoudhury RN, Hoff J, Goldblith SA, Proctor BE (1957) Milk 
Citation: Singh SK, Pavan MS, Sai Prasanna N, Kant R (2018) Applications of Super Critical Fluid Extraction in Milk and Dairy Industry: A Review. J Food Process Technol 9: 769. doi: 10.4172/2157-7110.1000769

irradiation, irradiation preservation of milk and milk products. Agric Food Chem 5: 944-950.

16. Matak KE, Sumner SS, Duncan SE, Hovingh E, Worobo RW, et al. (2007) Effects of ultraviolet irradiation on chemical and sensory properties of goat milk. J Dairy Sci 90: 3178-3186.

17. Elmnasser N, Dalgalarrondo M, Orange N, Bakhrouf A, Haertle T, et al. (2008) Effect of pulsed-light treatment on milk proteins and lipids. J Agric Food Chem 56: 1984-1991.

18. Pafylias I, Cheryan M, Mehaiab MA, Saglam N (1996) Microfiltration of milk with ceramic membranes. Food Res Int 29: 141-146.

19. Garcia LF, Rodriguez FAR (2014) Combination of microfiltration and heat treatment for ESL milk production: Impact on shelf life. J Food Eng 128: 1-9.

20. Chaudhari CB, Prajapati JP, Pinto SV. Ultrasound technology for dairy industry. National Seminar on "Indian Dairy Industry-Opportunities and Challenges".

21. Earnshaw RG, Appleyard J, Hurst RM (1995) Understanding physical inactivation processes: combined preservation opportunities using heat, ultrasound and pressure. Int J Food Microbiol 28: 197-219.

22. Mohamed RS, Mansoori GA (2002) The use of supercritical fluid extraction technology in food processing. Food Technol 20: 134-139.

23. Sahena F, Zaidul ISM, Jinap S, Karim AA, Abbas KA, et al. (2009) Application of supercritical $\mathrm{CO}_{2}$ in lipid extraction-a review. J Food Eng 95: 240-253.

24. Raventos M, Duarte S, Alarcon R (2002) Application and possibilities of supercritical $\mathrm{CO}_{2}$ extraction in food processing industry: An overview. Food Sci Technol Int 8: 269- 284

25. Chemat F, Rombaut N, Meullemiestre A (2017) Review of green food processing techniques. preservation, transformation and extraction. Innov Food Sci Emerg Technol 41: 357-377.

26. Ciftci ON (2017) Supercritical fluid technology: Application to food processing J Food Process Technol 3: e105.

27. da Silva RPFF, Rocha-Santos TAP, Duarte AC (2016) Supercritical fluid extraction of bioactive compounds. TrAC-Trends Anal Chem 76: 40-51.

28. National Dairy Council (1993) Newer knowledge of milk and other fluid dairy products, The Council, Rosemont, IL.

29. Evrendilek GA (2017) Non-thermal processing of milk and milk products for microbial safety: Dairy microbiology and biochemistry.

30. Sharma RK (1980) Effect of heat treatment on the nutritive value of milk. Indian Dairyman 32: 619-621.

31. Kankare V, Alkio M (1993) Removal of cholesterol during milk fat fractionation by supercritical carbon dioxide. Agric Sci Finl 2: 387-393.

32. Wolf WR, Croix DE, Goel R, Kaur M (2003) Total fat analysis in milk- and soybased infant Formula powder by supercritical fluid extraction. J Am Oil Chem Soc 80: 853-857.

33. Manganiello L, Rios A, Valcarcel M (2000) Automatic microgravimetric determination of fats in milk products by use of supercritical fluid extraction with on-line piezoelectric detection. J Chromatogr A 874: 265-274.

34. Turner C, Mathiasson L (2000) Determination of vitamins A and E in milk powder using supercritical fluid extraction for sample clean-up. J Chromatogr A 874: 275-283.

35. Haan AB, Graauw J (1990) Extraction of flavours from milk fat with supercritical carbon dioxide. J Supercrit Fluids 3: 15-19.

36. Yee JL, Khalil H, Flores RJ (2007) Flavor partition and fat reduction in cheese by supercritical fluid extraction: processing variables. Lait $87: 269-285$

37. Bhaskar AR, Rizvi SSH, Sherbon JW (1993) Anhydrous milk fat fractionation with continuous countercurrent supercritical carbon dioxide. J Food Sci 58: 748-752.

38. Deman JM (1968) Modification of milk fat by removal of high-triglyceride fraction. J Inst Can Tech 1: 1-93.

39. Deman JM (1961) Physical properties of milk fat. J Dairy Sci 28: 81-86.

40. Yoncoskie RA, Holsinger VH, Posati LP, Pallansch MJ (1969) Changes in thermal and optical properties of butter oil on hydrogenation. J Am Oil Chem Soc 46: 489-492.
41. Shishikura A, Fujimotto K, Kanedo T, Arai K, Saito S (1986) Modification of butter oil by extraction with supercritical $\mathrm{CO}_{2}$. Agri Bio Chem 50: 1209-1215.

42. Arul J, Bourdeau A, Makhlouf J, Tardif R, Sahasrabudhe MR (1987) Fractionation of anhydrous milk fat by superficial carbon dioxide. J Food Sci 52: $1231-1236$.

43. Arul J, Bourdeau A, Tardif R, Mcginnis DS, Lencki RW (1993) Solubility of milk fat triglycerides in supercritical carbon dioxide. Food Res Int 27: 459-467.

44. Perry ES, Weber WH, Daubert BF (1949) Vapour pressure of phlegmatic liquids: I. Simple and mixed triglycerides. J Am Chem Sot 71: 3720-3726.

45. Czubryt JJ, Myers MN, Giddings JC (1970) Solubility phenomena in dense carbon dioxide gas in the range 270-1900 atmospheres. J Phys Chem 74 4260-4266.

46. Costa MR, Argote XEE, Flores RJ, Gigante ML (2010) Use of ultrafiltration and supercritical fluid extraction to obtain a whey buttermilk powder enriched in milk fat globule membrane phospholipids. Int Dairy J 20: 598-602

47. Astaire JC, Ward R, German JB, Flores RJ (2003) Concentration of polar MFGM lipids from buttermilk by microfiltration and supercritical fluid extraction. J Dairy Sci 86: 2297-2307.

48. Spence AJ, Flores RJ, Qian M, Goddik L (2009) Evaluation of supercritical fluid extraction aids for optimum extraction of nonpolar lipids from buttermilk powder. J Dairy Sci 92: 5933-5936.

49. Barry KM, Dinan TG, Kelly PM (2017) Pilot scale production of a phospholipidenriched dairy ingredient by means of an optimised integrated process employing enzymatic hydrolysis, ultrafiltration and super-critical fluid extraction Innov Food Sci Emerg Technol 41: 301-306.

50. Amaral GV, Silva EK, Cavalcanti RN, Cappato LP, Guimaraes JT, et al. (2017) Dairy processing using supercritical carbon dioxide technology: Theoretical fundamentals, quality and safety aspects. Trend Food Sci Technol 64:94-101.

51. Berenhauser AC, Soares D, Komora N, Lindner JDD, Prudencio ES, et al. (2017) Effect of high-pressure carbon dioxide processing on the inactivation of aerobic mesophilic bacteria and Escherichia coli in human milk. CyTA-J Food 16: $122-126$.

52. Perrut M (2012) Sterilization and virus inactivation by supercritical fluids: A review. J Supercrit Fluid 66: 35-371

53. Giacomo GD, Taglieri L, Carozza P. Pasteurization and sterilization of milk by supercritical carbon dioxide treatment. University of L'Aquila, Italy.

54. Shamsi K, Versteeg C, Sherkat F, Shamsi JW (2008) Alkaline phosphatase and microbial inactivation by pulsed electric field in bovine milk. Innov Food Sci Emerg Technol 9: 217-223

55. Norton T, Sun DW (2008) Recent advances in the use of high pressure as an effective processing technique in the food industry. Food Bioprocess Techno 1: 2-34

56. Cenia G, Silva MF, Valerio C, Cansian RL, Oliveira JV, et al. (2016) Continuous inactivation of alkaline phosphatase and Escherichia coli in milk using compressed carbon dioxide as inactivating agent. $\mathrm{J} \mathrm{CO}_{2}$ Util 13: 24-28.

57. Hegsted DM (1991) in G.J. Nelson (Editor), Health Eft. Diet. Fatty Acids AOCS, Ch. 5 , p. 50

58. Sieber R (1993) Cholesterol removal from animal food-can it be justified? LWT Food Sci Technol 26: 375-387.

59. Sidhu GS, Oakenfull DG (1992) Cyclodextrin/cholesterol complexation and technology for removing cholesterol from eggs and dairy products. $6^{\text {th }}$ International Symposium on Cyclodextrins.

60. Huber W, Molero A, Pereyra C, Ossa MDL (1996) Dynamic supercritical CO extraction for removal of cholesterol from anhydrous milk fat. Int $\mathrm{J}$ Food Sci Technol 31:143-151.

61. Yeh An-I, Liang JH, Hwang LS (1991) Separation of fatty acid esters from cholesterol in esterified natural and synthetic mixtures by supercritical carbon dioxide. J Am Oil Chem Soc 68: 224-228.

62. Kosal E, Lee CH, Holder G (1992) Solubility of progesterone, testerone and cholesterol in supercritical fluids. J Supercrit Fluid 5: 169-179.

63. Yu ZR, Singh B, Rizvi SSH (1992) Fluid-liquid equilibria of anhydrous milk fat with supercritical carbon dioxide. J Supercrit Fluid 5: 123-129. 
Citation: Singh SK, Pavan MS, Sai Prasanna N, Kant R (2018) Applications of Super Critical Fluid Extraction in Milk and Dairy Industry: A Review. J Food Process Technol 9: 769. doi: 10.4172/2157-7110.1000769

64. Bradley Jr RL (1989) Removal of cholesterol from milk fat using supercritical carbon dioxide. J Dairy Sci 72: 2834-2840.

65. Shishikura A, Fujimoto K, Kaneda T (1986) Modification of butter oil by extraction with supercritical carbon dioxide. Agric Biol Chem 50: 1209-1215.

66. Huber W, Molero A, Pereyra C, Ossa MDL (1995) Determination of cholesterol in milk fat by supercritical fluid chromatography. J Chromatograph A 715: 333336.

67. Kankare V, Alkio M (1993) Removal of cholesterol during milk fat fractionation by supercritical carbon dioxide. Agric Sci Finland 2: 387-393.
68. Reza Al, Nodehi RN, Rastkari N, Aghamirloo HM (2017) Polychlorinated biphenyls (PCBs) residues in commercial pasteurized cows' milk in Tehran. J Environ Health Sci Eng 15: 1-6.

69. Mills AG, Jefferies TM (1993) Rapid isolation of polychlorinated biphenyls from a combination of supercritical-fluid extraction and supercritical-fluid chromatography. J Chromatograph 643:409-418.

70. Ramos L, Hernandez LM, Gonzalez MJ (2000) Study of the distribution of the polychlorinated biphenyls in the milk fat globule by supercritical fluid extraction. Chemosphere 41: 881-888. 